duration of follow-up was 15 months (range 3-59). At the end of the follow-up period, 10 of the 13 patients $(77 \%)$ were still in treatment. In 2 patients $(15 \%)$ the therapy failed, requiring lung transplantation in 1 case (after 7 months of therapy), while an autologous hematopoietic stem cell transplant was conducted in the other patient (after 13 months of antifibrotic). In one patient (8\%) the treatment was discontinued due to adverse effects.

When quantifying the degree of response in patients who continued treatment, only 9 of the 10 patients were included in the analysis, since 1 had only 3 months of therapy. In these 9 patients there was an improvement of\% pFVC (mean: +5.13; SD: 8.38) and\% pDLCO (+4.42; SD: 5.06). The evolution of the efficacy variables analyzed is shown in the table.

The response in the Pulmonary function testing (PFT) in these 9 patients categorized according to the definitions of the American Thoracic Society was as follows: A)\% pFVC: stabilization in 5 cases and improvement in 4; B)\% pDLCO: stabilization in 7 cases and improvement in 3 .

The frequency of adverse effects was $31 \%(4 / 13)$, but only the treatment was withdrawn in 1 patient $(8 \%)$. Three patients presented digestive discomfort that forced to reduce the dose of the antifibrotic. One patient developed a toxic hepatitis due to nintedanib after 4 months of treatment that forced the withdrawal of the drug, replacing it 1 month ago with pifernidone. None of the patients died during the follow-up period.

Conclusion: Our data provides evidence of the safety and tolerability of both pirfenidone and nintedanib in patients with DIDL-SAD refractory to GC and immunosuppressant therapy.

Disclosure of Interests: Marta Aguilar-Zamora: None declared, J. Narváez Consultant for: Bristol-Myers Squibb, Juanjo J Alegre-Sancho: None declared, Vanesa Vicens: None declared, Maria Molina: None declared, Joan Miquel Nolla: None declared

DOI: 10.1136/annrheumdis-2019-eular.7835

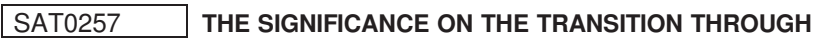 DIFFERENT PATTERNS OF NAILFOLD MICROVASCULAR DAMAGE ON THE COURSE OF SYSTEMIC SCLEROSIS}

Slavica Pavlov-Dolijanovic, Nemanja Damjanov, Nada Vujasinovic Stupar. Institute of Rheumatology, School of Medicine University of Belgrade, Belgrade, Serbia

Objective: To investigate the timing of transition through different patterns of nailfold microvascular damage in systemic sclerosis (SSc) patients and to determine the significance of this transition.

Methods: In the period January 2012 to December 2017, 400 SSc patients were followed up by nailfold videocapillaroscopy (NVC) the same operator (SPD) every 6 months. Demographic, clinical and laboratory data were recorded. The capillaroscopic findings were classsified as normal, nonspecific or scleroderma pattern ("early", "active", or "late"). The evolution on the NVC pattern over time was monitored and recorded.

Results: The transition of microvascular damage through different NVC patterns of microangiopathy was seen in 53/400 (13.25\%) SSc patients. At the baseline $11 / 53(21 \%)$ patients had the non-specific changes, the early pattern had $25 / 53(47 \%)$ patients, and the active pattern had $17 / 53$ $(32 \%)$ SSc patients. The mean \pm SD time of progression from one to another NVC patterns was $27.68 \pm 35.11$ months. Improvement of the NVC patterns was found in $15 / 53$ (28\%) patients and deterioration in the remaining $38(72 \%)$ patients. The mean time of progression from nonspecific to early pattern (in 10 patients) and non-specific to active pattern (in 1 patient) was $14.5 \pm 9.73$ vs. 12 months, respectively. Time of changed from early to nonspecific (in 7 patients), early to active (in 17 patients) and early to late pattern (in 1 patient) was $30.85 \pm 22.56$ vs $22.29 \pm 16.61$ vs 24 months, respectively. Time of changed from active to early (in 8 patients) and active to late pattern (in 9 patients), was $26.25 \pm 11.1$ vs $18.00 \pm 13.97$ months, respectively. Progression of nonspecific to early or active NVC pattern was related with limited form of SSc $(91 \%)$, diffuse hand swelling (54\%), arthralgia/arthirtis $(45 \%)$ and involvement of lungs (48\%). Also, progression of early to active NVC pattern was related with limited form of SSc (64\%), sclerodactyly (48\%) and involvement of lungs (48\%). In contrast, progression of active to late NVC pattern was related with diffuse form of SSc (53\%), digital ulcerations $(35 \%)$ and more frequent involvement of lungs $(65 \%)$. These differences in the frequency of involvement of certain organs were not statistically significant.

Conclusion: These results demonstrate dynamic transition of microvascular damage through different NVC patterns of microangiopathy in about $13 \%$ of SSc patients. Patients with rapid progression from the early to active, as well as active to the late NVC patterns ( $<2$ years) should be monitored closely, because they are at risk of further significant damage to the internal organs.

Disclosure of Interests: Slavica Pavlov-Dolijanovic: None declared, Nem anja Damjanov Grant/research support from: AbbVie, Pfizer and Roche, Consultant for: Abbvie, Gedeon Richter, Merck, Novartis, Pfizer and Roche., Speakers bureau: Abbvie, Gedeon Richter, Merck, Novartis, Pfizer and Roche., Nada Vujasinovic Stupar: None declared DOI: 10.1136/annrheumdis-2019-eular.2232

\section{SAT0258 SEXUAL HEALTH IMPAIRMENT IN WOMEN WITH SYSTEMIC SCLEROSIS}

Barbora Heřmánková ${ }^{1}$, Maja Špiritović ${ }^{1}$, Hana Smucrova ${ }^{2}$, Sabina Oreska ${ }^{2,3}$, Hana Štorkánová ${ }^{2,3}$, Kristyna Bubova ${ }^{2,3}$, Karel Pavelka ${ }^{2,3}$, Jiří Vencovskýn ${ }^{2,3}$, Ladislav Šenolt' ${ }^{2,3}$, Radim Bečváŕr, ${ }^{2,3}$, Michal Tomčík ${ }^{2,3}$. ${ }^{1}$ Faculty of Physical Education and Sport, Charles University, Prague, Czech Republic; ${ }^{2}$ Institute of Rheumatology, Prague, Czech Republic; ${ }^{3} 1$ st Faculty of Medicine, Charles University, Department of Rheumatology, Prague, Czech Republic

Background: Systemic sclerosis (SSc) is a chronic autoimmune disease that may affect all aspects of life including sexual function.

Objectives: To assess sexual function, pelvic floor function and sexual quality of life women with SSc compared to age-/sex-matched healthy controls $(\mathrm{HC})$. To subanalyze sexual function in sexually active individuals.

Methods: In total 47 women with SSc (mean age: 50.5, disease duration: 5.6 years, IcSSc/dcSSc: 27/20, mRSS: 12.7, ESSG activity index: 2.5), who fulfilled the ACR/EULAR 2013 criteria, and 47 healthy women (mean age: 50.5) filled in 11 well-established and validated questionnaires assessing sexual function, pelvic floor function, quality of life, fatigue, physical activity and depression. Data are presented as mean $\pm S E M$.

Results: Compared to $\mathrm{HC}$, patients with SSc had significantly higher prevalence and greater severity of sexual impairment (FSFI, BISF-W), pelvic floor dysfunction (PISQ-12, PFIQ7), and worse sexual quality of life (SQol-F) (table 1). There were no significant differences in sexual function between limited and diffuse SSc. Even sexually active SSc patients reported significantly greater sexual health impairment compared to sexu ally active HC. Sexual health impairment in SSc was associated with dis

Table 1.

\begin{tabular}{lcccccc}
\hline $\begin{array}{l}\text { Questionnaire: } \\
\text { score range }\end{array}$ & $\begin{array}{c}\text { SSc } \\
(\mathbf{n}=\mathbf{4 7})\end{array}$ & $\begin{array}{c}\text { HC } \\
(\mathbf{n}=\mathbf{4 7})\end{array}$ & $\mathrm{p}$-value & $\begin{array}{c}\text { SSc SA } \\
(\mathbf{n}=\mathbf{2 9})\end{array}$ & $\begin{array}{c}\text { HC SA } \\
(\mathbf{n}=\mathbf{2 9})\end{array}$ & $\mathrm{p}$-value \\
\hline FSFI :2(worst)-36 & 14.7 & 25.7 & $\mathrm{p}<0.0001$ & $20.6 \pm 1.7$ & $28.5 \pm 1,4$ & $\mathrm{p}<0.0001$ \\
(best) & \pm 1.6 & \pm 1.6 & & & & \\
BISF-W:-16(worst)- & 16.6 & 31.0 & $\mathrm{p}=0.0002$ & $25.7 \pm 2.8$ & $34.9 \pm 2.3$ & $\mathrm{p}=0.0143$ \\
75(best) & \pm 2.5 & \pm 2.6 & & & & \\
SQoL-F: 0(worst)- & 53.5 & 79.9 & $\mathrm{p}<0.0001$ & $58.0 \pm 5.0$ & $84.5 \pm 2.6$ & $\mathrm{p}<0.0001$ \\
100(best) & \pm 3.7 & \pm 3.1 & & & & \\
PISQ-12: 0(best)- & 14.6 & $8.4 \pm 0.6$ & $\mathrm{p}<0.0001$ & $13.6 \pm 1.0$ & $7.9 \pm 0.7$ & $\mathrm{p}<0.0001$ \\
48(worst) & \pm 0.9 & & & & & \\
PFIQ7: 0(best)-300 & 29.0 & $7.9 \pm 2.0$ & $\mathrm{p}=0.0075$ & $15.5 \pm 5.0$ & $9.3 \pm 2.8$ & $n \mathrm{~ns}$ \\
\hline
\end{tabular}

Abbreviations: FSFI: Female Sexual Function Index; BISF-W: Brief Index of Sexual Function for Women; SQoL-F: Sexual Quality of Life Questionnaire; PISQ-12: Pelvic Organ Prolapse/ Urinary Incontinence Sexual Questionnaire short form; PFIQ7: Pelvic Floor Distress

Inventory Questionnaire, SA: sexually active; ns:not significant

Table 2.

\begin{tabular}{|c|c|c|c|}
\hline Parameter: score range & Correlated parameters & $\mathbf{r}$ & $p$-value \\
\hline FIS (fatigue): & FSFI (sexual function) & -0.446 & $p=0.0016$ \\
\hline 0 (best)-160(worst) & BISF-W (sexual function) & -0.445 & $p=0.0016$ \\
\hline MAF (fatigue): 1(best)-50(worst) & $\begin{array}{l}\text { SQol-F (sexual quality of } \\
\text { life) }\end{array}$ & -0.415 & $\mathrm{p}=0.0050$ \\
\hline BDI-II (depression): & FSFI & -0.485 & $\mathrm{p}=0.0005$ \\
\hline \multirow[t]{3}{*}{0 (best)-63(worst) } & BISF-W & -0.483 & $p=0.0005$ \\
\hline & SQoL-F & -0.375 & $p=0.0119$ \\
\hline & PIFQ-7 (pelvic floor function) & 0.445 & $p=0.0017$ \\
\hline HAP (physical activity): & FSFI & 0.412 & $\mathrm{p}=0.0040$ \\
\hline 0 (worst)-94(best) & BISF-W & 0.398 & $p=0.0055$ \\
\hline SHAQ (scleroderma health status): & FSFI & -0.557 & $p<0.0001$ \\
\hline \multirow[t]{2}{*}{0 (best)-100(worst) } & BISF-W & -0.505 & $p=0.0002$ \\
\hline & PIFQ-7 & 0.429 & $p=0.0025$ \\
\hline $\begin{array}{l}\text { ESSG activity index: } 0 \text { (best)-10 } \\
\text { (worst) }\end{array}$ & $\begin{array}{l}\text { PISQ-12 (pelvic floor } \\
\text { function) }\end{array}$ & 0,322 & $p=0.0400$ \\
\hline Disease duration & PIFQ-7 & 0.361 & $p=0.0124$ \\
\hline
\end{tabular}

Abbreviations: FIS: Fatigue Impact Scale; MAF: Multidimensional Assessment of Fatigue; BDI-II: Beck's Depression Inventory II; HAP: Human Activity Profile; SHAQ: Scleroderma Health Assessment Questionnaire; ESSG: European Scleroderma Study Group 
ease activity/duration, health status, physical activity, fatigue and depression (table 2)

Conclusion: Women with SSc reported significantly impaired sexual func tion, sexual quality of life and pelvic floor function than age-matched $\mathrm{HC}$ Worse scores in SSc were associated with disease activity/duration/health status, physical activity, fatigue, and depression.

Acknowledgements: Supported by AZV-16-33574A, MHCR 023728.

Disclosure of Interests: Barbora Heřmánková: None declared, Maja Špiritović: None declared, Hana Smucrova: None declared, Sabina Oreska: None declared, Hana Štorkánová: None declared, Kristyna Bubova: None declared, Karel Pavelka: None declared, Jiř́ Vencovský Consultant for: Samsung, Speakers bureau: AbbVie, Novartis, Pfizer, Sanofi, Eli Lilly, Biogen, UCB, MSD, Werfen, Roche, Ladislav Šenolt Grant/research support from: AbbVie, Consultant for: AbbVie, Bristol-Myers Squibb, Celgene Corporation, Merck Sharp and Dohme, Novartis, Pfizer, Roche, UCB, Amgen, Takeda, Speakers bureau: AbbVie, Amgen, Bristol-Myers Squibb, Celgene Corporation, Eli Lilly, Merck Sharp and Dohme, Novartis, Pfizer, Roche, UCB, Radim Bečvář Consultant for: consultancy Actelion, Michal Tomčík: None declared

DOI: 10.1136/annrheumdis-2019-eular.4979

\section{SAT0259 $\quad$ PREDICTIVE FACTORS FOR TREATMENT RELATED MORTALITY AND MAJOR ADVERSE EVENTS AFTER AUTOLOGOUS HEMATOPOIETIC STEM CELL TRANSPLANTATION FOR SYSTEMIC SCLEROSIS: RESULTS OF A LONG TERM FOLLOW-UP MULTI- CENTRE STUDY}

Sandra van Bijnen ${ }^{1}$, Maaike Boonstra ${ }^{2}$, Cornelia van den Enden ${ }^{1}$, Julia Spierings ${ }^{3}$ Anne Schouffoer ${ }^{2}$, Jacob M. van Laar ${ }^{3}$, Thomas Huizinga ${ }^{2}$, Alexandre Voskuyl ${ }^{4}$, Walter van der Velden ${ }^{5}$, Frank van den Hoogen ${ }^{1}$, Jeska de Vries ${ }^{2}$, Madelon Vonk ${ }^{1}$. ${ }^{1}$ Radboud University Medical Center, Rheumatic diseases, Nijmegen, Netherlands ${ }^{2}$ Leiden University Medical Center (LUMC), Rheumatology, Leiden, Netherlands; ${ }^{3}$ University Medical Center Utrecht, Rheumatology, Utrecht, Netherlands; ${ }^{4}$ VUmc, Rheumatology, Amsterdam, Netherlands; ${ }^{5}$ Radboud University Medical Center, Hematology, Nijmegen, Netherlands

Background: Autologous hematopoietic stem cell transplantation (HSCT) has shown superior efficacy to cyclophosphamide pulse therapy in systemic sclerosis (SSc) but its application is hampered by high treatment related mortality (TRM). To date factors, other than smoking, predicting TRM are unknown.

Objectives: To describe event-free survival and TRM after HSCT and to evaluate the predictive value of baseline characteristics. Event-free survival was defined as the absence of mortality or major organ failure (i.e. cardiac failure (left ventricular ejection fraction (LVEF) $<30 \%$, respiratory failure (resting $\mathrm{PaO} 2<8 \mathrm{kPa} / 60 \mathrm{~mm} \mathrm{Hg}$ or $\mathrm{PaCO} 2>6,7 \mathrm{kPa}$ or chronic oxygen supplementation), or renal failure requiring dialysis.

Methods: All patients who started with the procedure of HSCT for SSC in the Netherlands between 1.1.1998 and 31.12.2016 were included. Except in 4 patients, eligibility criteria and procedures of the ASTIS trial were used (1). A Kaplan-Meier event-free survival curve was constructed. All deceased patients were discussed in a consensus meeting, to determine the cause of death as TRM, progression of SSc or other. The univariate association of TRM and event-free survival with baseline characteristics (gender, age, disease duration, smoking ever, FVC, DLCO, LVEF) was examined by Cox regression analysis.

Results: 92 patients were included, including 4 patients with limited cutaneous subtype who were treated because of interstitial lung disease. The median (IQR) follow-up time was 4.5 (2.3 - 12.3) years. Twenty patients died during the observation period of whom $10(10.8 \%, 9$ males) in the first year because of TRM. Twelve patients (13.1\%) developed major organ failure (6 lung, 3 kidney and 3 heart) of whom 8 died during the

Table 1:. demographic and disease related factors

\begin{tabular}{lc}
\hline Male/female & $49 / 43$ \\
\hline LcSSc/DcSSc & $4 / 88$ \\
Age at HSCT mean (SD) (year) & $46.8(10.3)$ \\
Disease duration at HSCT mean (SD)(year) & $2.4(2.4)$ median 1.6 \\
mRSS mean (SD) & $26(10.1)$ \\
Antibodies: ANA, ATA, Anti-RNAP positive & $88 / 92 ; 34 / 92 ; 1 / 92$ \\
Ever smoker & $54 / 84$ \\
FVC as\% pred. mean (SD) & $84.9(22.7)$ \\
DLCO as\% pred mean (SD) & $55.1(16.2)$ \\
LVEF $<50 \%$ (by echo) & $3 / 92$
\end{tabular}

observation period. Event-free survival after five and ten years was 68\% (40/59 patients) and 59\% (30/51), respectively. TRM was significantly associated with male gender (HR $(95 \% \mathrm{Cl})$ : $8.7(1.1-68.9)$, but not with smoking; events were associated with male gender, older age and LVEF $<50 \%$ at baseline (HR: $4.08(1.5-11.0) ; 1.1(1.0-1.1)$ and 4.7 (1.1 20.6), respectively).

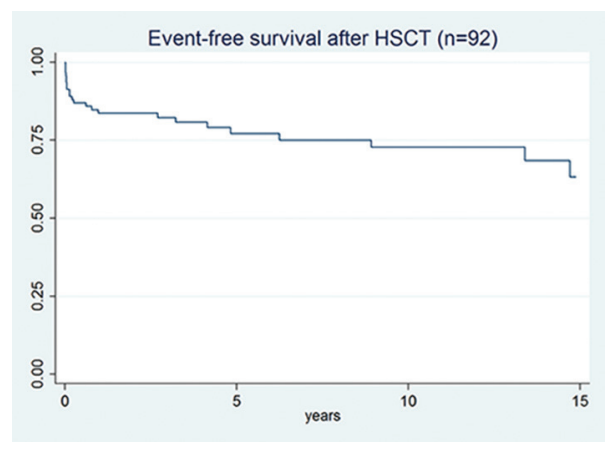

Conclusion: In this national cohort study of HCST in patients with SSC and poor prognosis we observed a median event-free survival of 4.3 years. TRM was $10,8 \%$ and major events occurred in 13\%. TRM was correlated to male gender. Low LVEF, male gender and older age were correlated with major events.

\section{REFERENCES}

[1] van Laar JM, Farge D, Sont JK, et al. Autologous hematopoietic stem cell transplantation vs intravenous pulse cyclophosphamide in diffuse cutaneous systemic sclerosis: a randomized clinical trial. JAMA. 2014;311 (24):2490-8.

Disclosure of Interests: Sandra van Bijnen: None declared, Maaike Boonstra: None declared, Cornelia van den Enden: None declared, Julia Spierings Grant/research support from: Boehringer Ingelheim, Anne Schouffoer: None declared, Jacob M. van Laar Grant/research support from: Genentech, Consultant for: F. Hoffmann-La Roche, Thomas Huizinga Consultant for: Merck, UCB, Bristol Myers Squibb, Biotest AG, Pfizer, GSK, Novartis, Roche, Sanofi-Aventis, Abbott, Crescendo Bioscience Inc., Nycomed Boeringher, Takeda, Zydus, Epirus, Eli Lilly, Alexandre Voskuyl: None declared, Walter van der Velden: None declared, Frank van den Hoogen: None declared, Jeska de Vries: None declared, Madelon Vonk Grant/ research support from: Madelon Vonk has received unrestricted research funds from Actelion and Therabel, Consultant for: Madelon Vonk was a consultant for Actelion, Boehringer-Ingelheim, Speakers bureau: Actelion, Boehringer-Ingelheim, Roche

DOI: 10.1136/annrheumdis-2019-eular.5380

\section{SAT0260 MUSCULAR INVOLVEMENT OF THE LOWER LIMBS IN PATIENTS WITH IDIOPATHIC INFLAMMATORY MYOPATHIES: A MRI EVALUATION}

Simone Barsotti ${ }^{1}$, Barbara Mugellini ${ }^{2}$, Alessandra Tripoli ${ }^{1}$, Giacomo Aringhieri ${ }^{2}$ Chiara Cardelli ${ }^{1}$, Elisa Cioffi ${ }^{1}$, Virna Zampa ${ }^{2}$, Davide Caramella ${ }^{2}$, Marta Mosca ${ }^{1}$, Rossella Neri ${ }^{1} .{ }^{1}$ University of Pisa, Rheumatology Unit, Pisa, Italy; ${ }^{2}$ University of Pisa, I radiology Unit, Pisa, Italy

Background: Since many years, muscular magnetic resonance imaging (MRI) has been used in the diagnosis and follow-up of patients with idiopathic inflammatory myopathies (IIM), but the clinical significance and the pattern of the muscular alterations (edema, fatty infiltration and atrophy) in different subsets of the disease are still not well defined.

Objectives: The aims of this study were to analyse possible differences in the involved muscles between dermatomyositis (DM) and polymyositis (PM); the correlations between the pattern of muscular involvement in dif ferent subsets of the disease and disease parameters in a monocentric cohort of patients.

Methods: We retrospectively collected data from 85 patients with poly and dermatomyositis (EULAR/ACR criteria) who performed pelvic and tights muscle MRI from January 2010 to December 2018: 27 had DM and $58 \mathrm{PM}$, mean age $58.6 \pm 13.4$ years, mean disease duration of $45 \pm 73$ months. The images in 22 muscles for the presence of muscular edema, fatty infiltrates and atrophy were assessed by a dedicated radiologist. Moreover, data about serum creatine kinase (CK) and manual muscle 